\title{
Psyllium and fat in diets differentially affect the activities and expressions of colonic sphingomyelinases and caspase in mice
}

\author{
Yajun Cheng, Lena Ohlsson and Rui-Dong Duan* \\ Gastroenterology and Nutrition Laboratory, Biomedical Centre, B11, Lund University, S-22184 Lund, Sweden
}

(Received 14 August 2003 - Revised 22 December 2003 - Accepted 29 January 2004)

\begin{abstract}
Dietary fibre and fat affect colonic tumourigenesis and inflammation. Sphingomyelin metabolism may have implications for the pathogenesis of colonic tumours and ulcerative colitis. The present study examined the effects of psyllium and fat on the enzymes responsible for sphingomyelin metabolism and apoptosis in the colon. Mice were fed control, psyllium-containing (100 g/kg), high-fat (313 g/kg, $53 \%$ energy as fat) or high-fat plus psyllium diets for 4 weeks. The activities of acid, neutral and alkaline sphingomyelinase (SMase), neutral ceramidase, and caspase 3, 8 and 9 in colonic mucosa were determined. The expressions of alkaline SMase and caspase 3 were examined. The psyllium-containing diet was found to increase significantly the activities of alkaline SMase and caspase 3 and decreased those of acid SMase and neutral ceramidase. The high-fat diet had opposite effects on these enzymes and attenuated the effects of psyllium. Western blotting showed that psyllium increased and high-fat decreased the levels of alkaline SMase and caspase 3 in colonic mucosa. The change in caspase 3 activity was positively correlated with that of alkaline SMase and negatively with acid SMase. No similar changes of acid and alkaline phosphatase activities in the colon or acid and neutral SMase activity in the liver were identified. In conclusion, colonic sphingomyelin metabolism and apoptosis were affected by psyllium and fat in an opposite manner. The results may have implications for colorectal tumourigenesis and inflammation.
\end{abstract}

Psyllium: Fat: Sphingomyelinase: Colon

Sphingomyelin (SM) is a type of sphingolipid. It is present in all eukaryotic cells and in dietary products such as milk, egg and meat (Zeisel et al. 1986; Blank et al. 1992). SM is hydrolysed sequentially by sphingomyelinase (SMase) and ceramidase to ceramide and sphingosine, which are considered to be major anti-proliferative molecules affecting tumourigenesis (Hannun \& Bell, 1989; Kolesnick, 1991; Merrill et al. 1997). In the intestinal tract there are three types of SMase: acid, neutral and alkaline. Our previous studies have shown that alkaline SMase is specifically expressed in the intestinal mucosa and located on the surface of the brush border (Nilsson, 1969; Duan et al. 1995, 2003; Cheng et al. 2002). We also identified a neutral ceramidase in the gut that is distributed in parallel with alkaline SMase (Nilsson, 1969; Lundgren et al. 2001). The alkaline SMase and neutral ceramidase are the major enzymes that are responsible for digestion of sphingolipids in the gut (Nyberg et al. 1997; Duan et al. 2001).

Digestion of dietary SM may have clinical implications. Supplementary SM in the diet has been shown to inhibit colonic tumourigenesis in animals treated with 1,2dimethylhydrazine (Dillehay et al. 1994). In the tissues of human adenomas, carcinomas and longstanding ulcerative colitis, the activities of alkaline SMase were decreased (Hertervig et al. 1996, 1999; Sjöqvist et al. 2002; Duan et al. 2003). The reduced alkaline SMase activity may affect SM digestion, decrease the level of ceramide and increase the susceptibility of colonic mucosa to carcinogenic factors.

It is well known that the development of colon cancer is determined by the interplay of genetic and environmental factors. The influence of dietary components, particularly fat and fibre, has gained great attention. Based on most (but not all) ecological and epidemiological studies, case-control and cohort studies, and studies of migrants and laboratory animals, it is generally suggested that a high-fat diet increases, and a high-fibre diet decreases, the risk of colon cancer. The effect of fat varies with the type of the fat and the composition of fatty acids: saturated fat is most noxious. The effects of fibre are also dependent on the type and the metabolism of the fibre in the gut. The detailed background of the effects of dietary fat and fibre on pathogenesis of colorectal cancer has been summarised in several excellent reviews (Lipkin et al. 1999; Kim, 2000; Reddy et al. 2003). In addition to effects on tumourigenesis, dietary factors may also affect the process of colonic inflammation. A high-fat diet has been reported to increase the risk of ulcerative colitis (Reif et al. 1997; Geerling et al. 2000) and dietary fibre may prolong the remission of the inflammation (Fernandez-Banares et al. 
1999; Kanauchi et al. 2002). The mechanism underlying the effects of the dietary factors on colon cancer and intestinal bowel disease has not been well established, although the alterations of the colonic concentrations of bile salts, $\mathrm{Ca}$ and carcinogens may be involved, and the changed expression of Cox 2 and ras have been suggested (Reddy et al. 2003). We have previously shown that the insoluble fibre cellulose in a high-fat diet influenced the activities of acid and neutral, but not alkaline, SMase (Yang et al. 2002). However, whether high dietary fat per se and whether other types of fibre affect SMase (particularly alkaline SMase) activity remains elusive.

Psyllium is a type of water-soluble fibre derived from Plantago ovata. Psyllium husks are pure dietary fibres, composed mostly of hemicellulose. They are not digested in the small intestine and are partially broken down in the colon, where they act as a food source for normal bacterial flora and increase the bulk of the stool. Psyllium has been used for intestinal health in Europe since the 16th century with few harmful side effects reported. Recently psyllium has been found to have anti-carcinogenic and anti-inflammatory effects in the colon (Robert-Andersen et al. 1987; Alabaster et al. 1993; Cohen et al. 1996; Fernandez-Banares et al. 1999). As SM metabolism has been found to be altered in both colorectal cancer and colitis, the present study was designed to study the effects of psyllium and fat on the activities and expression of the enzymes that are responsible for SM digestion and apoptosis in the colon.

\section{Materials and methods}

\section{Materials}

The experiment was approved by the Animal Ethics Committee of the Medical Faculty, Lund University. Mice (Balb/c) at the age of 4 weeks were obtained from M\&B (Ry, Denmark). Purified psyllium was provided by Dr Falk Pharma GmbH (Freiburg, Germany). [ $\left.{ }^{14} \mathrm{C}\right]$ choline-labelled SM $(2 \cdot 1 \mathrm{MBq} /$ mg) was provided by Dr Lena Nyberg (Skåne Dietary Association, Malmö, Sweden). Anti-human alkaline SMase antibody was developed in the laboratory as described by Duan et al. (2003) and anti-caspase 3 antibody was purchased from Calbiochem (San Diego, CA, USA). The substrates of caspase 3 (aspartate-glutamate-valine-aspartate-pentose nucleic acid), caspase 8 (acetyl-isoleucine-glutamate-threonine-aspartate- $p$-nitroaniline) and caspase 9 (acetyl-leucine-glutamate-histidine-aspartate-pentose nucleic acid) were purchased from Upstate Biotech (Lake Placid, NY, USA). $\left[{ }^{14} \mathrm{C}\right]$ octanoic acid was purchased from American Radiolabeled Chemicals Inc (St Louis, MO, USA). The materials for preparation of experimental diets were obtained from ICN (Stockholm, Sweden), except butter, sunflower seed oil and rapeseed oil, which were purchased from the local supermarket.

\section{Experimental diets and animals}

Four types of semisynthetic diets were prepared. The control and high-psyllium $(100 \mathrm{~g} / \mathrm{kg})$ diets were modified AIN93G diets (Reeves et al. 1993) and were similar with regard to protein, fat and carbohydrate content. The highfat diet was prepared by enriching the diet with butter and rapeseed oil, but still providing $3 \%$ energy from sunflower seed oil to prevent symptoms of essential fatty acid deficiency (Pajari \& Mutanen, 1999). The high-fat plus psyllium diet was prepared by addition of psyllium $(100 \mathrm{~g} / \mathrm{kg})$ to the high-fat diet. The composition and the $\%$ macronutrients as energy of the experimental diets are shown in Tables 1 and 2. All the diets were designed to be comparable in terms of the amounts of protein and fat, both in relation to weight and energy content. The prepared diets were stored at $-20^{\circ} \mathrm{C}$ and given daily in excess to the mice.

Forty-eight mice were divided into four groups and each group was given one type of diet for 4 weeks. The body weight of the animal was determined weekly. The mice were killed by cervical dislocation. The colon was removed and the colonic mucosa was scraped and homogenised as described by Duan et al. (1995). The homogenate was further sonicated for $10 \mathrm{~s}$ followed by centrifugation at 15000 relative centrifugal force for $15 \mathrm{~min}$. The supernatant fraction was saved for analysis of SMase and caspase. Four animals in each group were randomly selected for measurement of expression of the enzymes by Western

Table 1. Dietary composition $(\mathrm{g} / \mathrm{kg})$

\begin{tabular}{lcccc}
\hline Components & Control & Psyllium & High-fat & High-fat + psyllium \\
\hline Casein & 217 & 196 & 278 & 250 \\
Dextrose & 360 & 324 & 209 & 188 \\
Starch & 294 & 265 & 139 & 125 \\
Total carbohydrate & 654 & 589 & 348 & 313 \\
Butter & 0 & 0 & 208 & 188 \\
Sunflower seed oil & 42 & 38 & 18 & 16 \\
Rapeseed oil & 33 & 30 & 36 & 78 \\
Total fat & 75 & 68 & 313 & 282 \\
Psyllium & 0 & 100 & 41.6 & 100 \\
Mineral mix & 368 & 9.5 & 11.8 & 37.4 \\
Vitamin mix & 10.5 & $2 \cdot 8$ & 3.6 & 10.6 \\
L-Cystine & 3.2 & 2.8 & 3.6 & 3.2 \\
Choline chloride & 3.2 & 0.14 & 0.14 & 3.2 \\
BHT & 0.14 & & & 0.14 \\
\hline
\end{tabular}

$\mathrm{BHT}$, butylated hydroxytoluene. 
Table 2. Dietary composition (\% energy)

\begin{tabular}{lccc}
\hline Diet & Protein & Carbohydrate & Fat \\
\hline Control & 20.89 & 62.88 & 16.23 \\
Psyllium & 20.90 & 62.88 & 16.22 \\
High-fat & 20.90 & 26.16 & 52.93 \\
High-fat + psyllium & 20.90 & 26.16 & 52.94 \\
\hline
\end{tabular}

blot before feeding. The livers in all animals were also removed and homogenised similarly.

\section{Sphingomyelinase assay}

The alkaline SMase activity was determined as described by Duan \& Nilsson (1999). In brief, a $5 \mu l$ sample was added to $95 \mu l 50 \mathrm{~mm}$-Tris-buffer containing $0.15 \mathrm{M}-\mathrm{NaCl}$, $2 \mathrm{~mm}$-EDTA, $6 \mathrm{~mm}$-sodium taurocholate and $80 \mathrm{pmol}$ $\left[{ }^{14} \mathrm{C}\right] \mathrm{SM}(133 \mathrm{~Bq}), \mathrm{pH} 9 \cdot 0$. The reaction was stopped by the addition of $0.4 \mathrm{ml}$ chloroform-methanol $(2: 1, \mathrm{v} / \mathrm{v})$ followed by centrifugation at 10000 relative centrifugal force for $10 \mathrm{~s}$. A portion of the upper phase was taken and the production of $\left[{ }^{14} \mathrm{C}\right]$ phosphocholine was determined by liquid scintillation. The activities of acid and neutral SMase were determined in a similar way in modified buffers. The acid SMase was assayed in $50 \mathrm{mM}$-maleate buffer containing $0.15 \mathrm{M}-\mathrm{NaCl}$, Triton X100 ( $1 \cdot 2 \mathrm{~g} / \mathrm{l})$, pH 5.0; neutral SMase was assayed in $50 \mathrm{mM}-\mathrm{HCl}$ buffer containing $4 \mathrm{~mm}-\mathrm{Mg}^{2+}$ and Triton X100 (1.2 g/l), pH 7.5.

\section{Synthesis of D-erythro- $\left[{ }^{14}\right.$ C]octanoyl ceramide and ceramidase assay}

1- $\left[{ }^{14} \mathrm{C}\right]$ octanoyl ceramide was prepared according to Bielawska \& Hannun (2000) with modification. $\left[{ }^{14} \mathrm{C}\right]$ octanoic acid $(3.8 \mu \mathrm{mol})$ was dried and reacted with $38 \mu \mathrm{mol}$ octanoyl chloride in $0.5 \mathrm{ml}$ benzene for $2 \mathrm{~h}$. The solution was dried under $\mathrm{N}_{2}$ and reacted with $25 \mathrm{mg}$ D-erythrosphingosine in $2.5 \mathrm{ml}$ tetrahydrofuran and $1.25 \mathrm{ml}$ sodium acetate $(500 \mathrm{~g} / \mathrm{l})$ for $4 \mathrm{~h}$ with stirring. The reaction was terminated by adding $6 \mathrm{ml}$ chloroform, $3 \mathrm{ml}$ methanol and $2.25 \mathrm{ml}$ water. The labelled $1-\left[{ }^{14} \mathrm{C}\right]$ octanoyl ceramide present in the lower phase was purified by TLC and the plate (Whatman ${ }^{\circledR}$, Maidstone, Kent, UK; $150 \AA$, $0.5 \mathrm{~mm}$ ) was developed by chloroform-methanol-2 M-ammonium hydroxide (4.0:1.0:0 1, by vol.). The specific activity of the labelled ceramide was about $183 \mathrm{~Bq} / \mathrm{nmol}$.

For ceramidase assay, $1-\left[{ }^{14} \mathrm{C}\right]$ octanoyl ceramide was dried under $\mathrm{N}_{2}$, suspended in $50 \mathrm{~mm}$-Tris-maleate buffer, $\mathrm{pH} 7 \cdot 0$, containing $10 \mathrm{~mm}$-sodium taurocholate (assay buffer), and sonicated for $2 \mathrm{~min}$ on iced water. A $10 \mu \mathrm{l}$ sample was mixed with $90 \mu \mathrm{l}$ assay buffer containing 2 nmol 1$\left[{ }^{14} \mathrm{C}\right]$ octanoyl ceramide, followed by incubation at $37^{\circ} \mathrm{C}$ for $1 \mathrm{~h}$. The reaction was interrupted by addition of $0.6 \mathrm{ml}$ methanol-chloroform-heptane (28:25:20, by vol.) and $0.2 \mathrm{ml}$ $0.05 \mathrm{M}-\mathrm{K}_{2} \mathrm{CO}_{3} / \mathrm{K}_{2} \mathrm{~B}_{2} \mathrm{O}_{2}$, pH 10. After centrifugation at 10000 relative centrifugal force for $10 \mathrm{~s}, 200 \mu \mathrm{l}$ upper phase were taken for liquid scintillation counting. In the upper phase about $90 \%$ of fatty acids was recovered under these conditions. This incomplete recovery was adjusted for in subsequent calculations (Lundgren et al. 2001).

\section{Caspase assay}

The activities of caspase 3,8 and 9 were determined as described previously (Liu et al. 2002) in a buffer containing $50 \mathrm{~mm}$-HEPES, $100 \mathrm{~mm}-\mathrm{NaCl}, \quad 3-((3$-cholamidopropyl) dimethylammonio)-1-propane-sulfonate $(1 \mathrm{~g} / \mathrm{l}), 10 \mathrm{mM}-$ dithiothrietol, $0 \cdot 1 \mathrm{~mm}$-EDTA, glycerol $(100 \mathrm{~g} / \mathrm{l})$ and $2 \mathrm{~mm}$ specific substrates, $\mathrm{pH} 7 \cdot 4$. The cleavage of the substrates was determined by the absorbance at $405 \mathrm{~nm}$ on a microplate reader (Bio-Rad, Stockholm, Sweden) every $30 \mathrm{~min}$ up to $2 \mathrm{~h}$, using $p$-nitroaniline as a standard. The activities were expressed as the production of $p$-nitroaniline/min per $\mathrm{mg}$ sample protein.

\section{Western blotting}

Western blotting of alkaline SMase was performed as described by Duan et al. (2003). Protein $(50 \mu \mathrm{g})$ in each sample was resolved by SDS (100 g/l)-PAGE and transferred to nitrocellulose membrane electrophoretically. The membrane was probed with polyclonal rabbit antihuman alkaline SMase antibody (1:500 dilution) and then with goat anti-rabbit antibody conjugated with alkaline phosphatase. For Western blotting of caspase 3, $50 \mu \mathrm{g}$ protein in each sample was subjected to SDS (150 g/l)-PAGE and then transferred to nitrocellulose membrane as described earlier. The membrane was then incubated with mouse anti-caspase 3 antibody (1:2000) overnight and then with goat anti-mouse antibody conjugated with alkaline phosphatase for $2 \mathrm{~h}$. The bands were visualised by a kit obtained from Bio-Rad. The densities of the bands were quantified by Scion Image Software after transforming the files to TIF format. The program was obtained from Scion Co. (www.scioncorp.com).

Table 3. The body weight (g) of mice fed different types of diets for 4 weeks ${ }^{*} \dagger$ (Mean values and standard deviations for twelve mice per group)

\begin{tabular}{|c|c|c|c|c|c|c|c|c|c|c|}
\hline \multirow{2}{*}{ Diet } & \multicolumn{2}{|c|}{ Week 0} & \multicolumn{2}{|c|}{ Week 1} & \multicolumn{2}{|c|}{ Week 2} & \multicolumn{2}{|c|}{ Week 3} & \multicolumn{2}{|c|}{ Week 4} \\
\hline & Mean & $\mathrm{SD}$ & Mean & $\overline{S D}$ & Mean & $\overline{S D}$ & Mean & SD & Mean & SD \\
\hline Control & $16 \cdot 59$ & 1.70 & 17.43 & 1.83 & $18 \cdot 37$ & 1.63 & 19.63 & 1.73 & $20 \cdot 15$ & $1 \cdot 80$ \\
\hline Psyllium & $17 \cdot 16$ & 1.56 & 17.68 & 1.63 & 17.92 & 1.42 & 18.50 & 1.45 & $19 \cdot 31$ & 1.56 \\
\hline High-fat & $16 \cdot 68$ & 1.45 & 17.44 & 1.56 & 18.62 & 1.73 & 19.50 & 1.80 & $20 \cdot 08$ & 1.73 \\
\hline High-fat + psyllium & $16 \cdot 83$ & 0.87 & $17 \cdot 82$ & 0.90 & $18 \cdot 82$ & 0.69 & $19 \cdot 38$ & 0.87 & $20 \cdot 22$ & 0.73 \\
\hline
\end{tabular}

${ }^{\star}$ For details of diets and procedures, see Tables 1 and 2 and p. 716.

†The body weights were determined weekly. 


\section{Other biochemical analyses}

The activities of acid and alkaline phosphatases were determined as described previously using $p$-nitrophenyl phosphate as a substrate (Cheng et al. 1999). The proteins in the homogenate were analysed using DC protein assay kit obtained from Bio-Rad.

\section{Statistical analyses}

Results are presented as mean values and standard deviations. The results from the psyllium and high-fat groups were compared with those from the control group. The results from the high-fat group were also compared with those from the high-fat plus psyllium group. The statistical significance $(P<0.05)$ of the difference for alkaline SMase and caspase activities between each comparison was determined by unpaired Student's $t$ test. The results of Western blotting were non-parametric data and the significance of differences of the band density was determined by Wilcoxon-Mann-Whitney test. $P<0 \cdot 05$ was considered to be statistically significant.

\section{Results}

\section{Changes in body weight}

The changes in body weights of mice in each dietary group are shown in Table 3 . There was no statistical significance in the animals' body weight in different groups during the experiment, although the gain in body weight of the mice in the psyllium group was less than those in other groups.

\section{Changes of sphingomyelinase activities}

The changes in alkaline, acid and neutral SMase activities induced by the diets are shown in Fig. 1. Compared with the control group, the psyllium-containing diet significantly increased the activity of alkaline SMase by $57 \%(P<0.05)$ and reduced that of acid SMase by $32 \%(P<0.001)$. Conversely, the high-fat diet sharply reduced the activity of alkaline SMase by $64 \%(P<0.01)$, but increased that of acid SMase by $13 \%(P<0 \cdot 05)$. The effect of fat on alkaline SMase was partially reversed (and that on acid SMase was totally reversed) by addition of psyllium in the diet. Both high-fat and psyllium-containing diets did not affect neutral SMase activity.

\section{Changes of caspase activities}

The activities of caspase after feeding the diets are shown in Fig. 2. Compared with the control diet, the addition of $100 \mathrm{~g}$ psyllium $/ \mathrm{kg}$ significantly increased the activity of caspase 3 by about $100 \%(P<0.05)$ and increased that of caspase 8 slightly (NS). The high-fat diet significantly reduced the activities of caspase 3,8 and 9 by 73 $(P<0.01), 52(P<0.05)$ and $47 \%(P<0.01)$ respectively. The reductions caused by fat were partly reversed by psyllium in the high-fat plus psyllium diet.
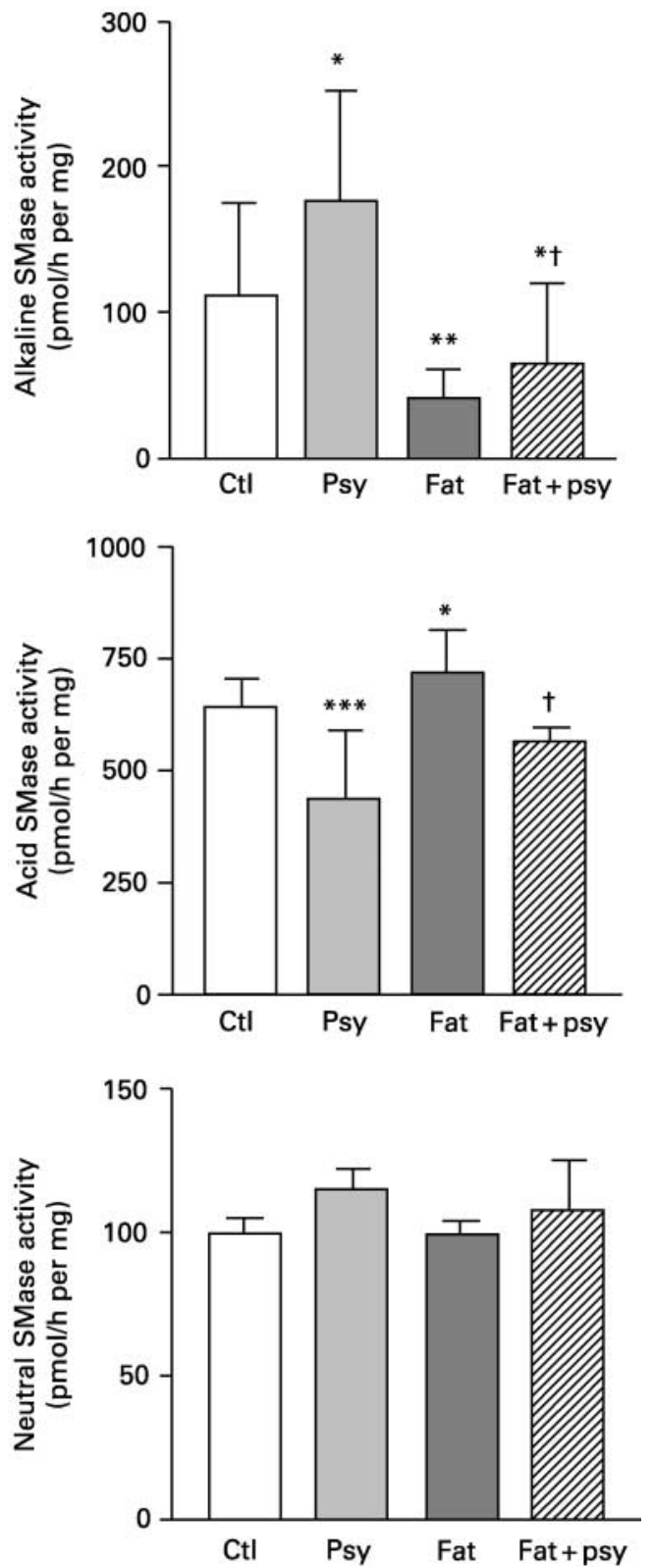

Fig. 1. Activities of sphingomyelinase (SMase) in colonic mucosa of mice (twelve per group) fed control (Ctl), psyllium-containing (Psy), high-fat (Fat) or high-fat plus psyllium (Fat + psy) diets for 4 weeks. The colonic mucosa was scraped and homogenised. The activities of acid, neutral and alkaline SMase were determined using $\left[{ }^{14} \mathrm{C}\right]$ choline-labelled sphingomyelin as substrate. For details of diets and procedures, see Tables 1 and 2 and pp. 716-717. Values are means with standard deviations shown by vertical bars. Mean values were significantly different from those of the control group: ${ }^{\star} P<0.05$, ${ }^{* \star} P<0.01$, ${ }^{\star * \star} P<0.001$. Mean values were significantly different from those of the high-fat group: $† P<0.05$.

\section{Expressions of alkaline sphingomyelinase and caspase 3 by} high-fat and psyllium-containing diets

To assess whether the changed activities of alkaline SMase and caspase 3 were associated with decreased expressions of the enzymes, Western blotting was performed in four randomly selected samples in each group. Fig. 3(a) shows representative results of Western blots and Fig. 3(b) shows the densities of alkaline SMase and caspase 3 

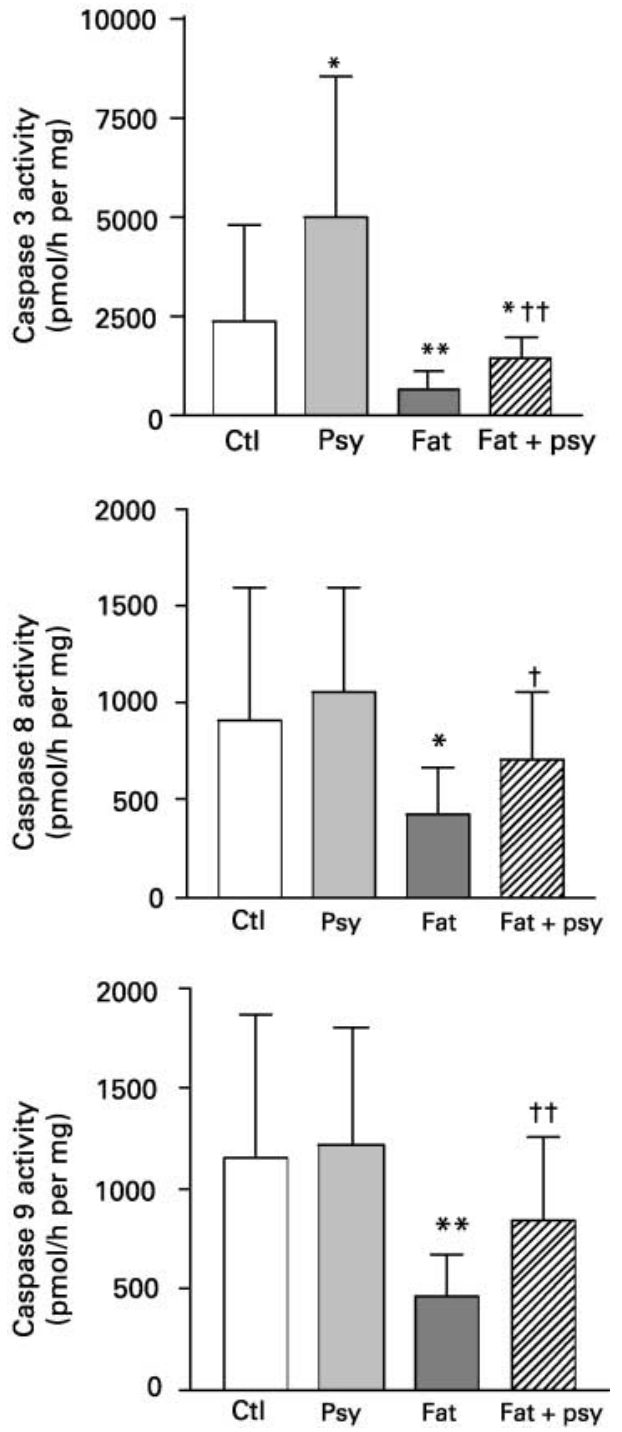

Fig. 2. Activities of caspases in colonic mucosa of mice (twelve per group) fed control (Ctl), psyllium-containing (Psy), high-fat (Fat) or high-fat plus psyllium (Fat + psy) diets for 4 weeks. The colonic mucosa was scraped and homogenised. The activities of caspase 3,8 and 9 were determined using specific substrates. For details of diets and procedures, see Tables 1 and 2 and pp. 716-717. Values are means with standard deviations shown by vertical bars. Mean values were significantly different from those of the control group: ${ }^{\star} P<0.05$, ${ }^{\star \star} P<0.01$. Mean values were significantly different from those of the high-fat group: $\dagger P<0.05, \uparrow \dagger P<0.01$.

bands in these samples. The levels of alkaline SMase were significantly increased by psyllium $(P<0.05)$ and decreased by the high-fat diet $(P<0 \cdot 05)$. The caspase 3 levels were also significantly increased $(P<0.05)$ by the psyllium-containing diet. The levels of caspase 3 appeared to be reduced by the high-fat diet, although the changes were not statistically significant $(P=0.057$, Wilcoxon-Mann-Whitney test). In Western blot for caspase 3 we detected the presence of pro-caspase 3 (Fig. 3 (a)), but not the cleaved active form.

\section{Changes in neutral ceramidase activity}

The effects of the diets on neutral ceramidase activity are shown in Fig. 4. In comparison with the control diet, the (a)

A $\quad$ B $\quad$ C $\quad$ D
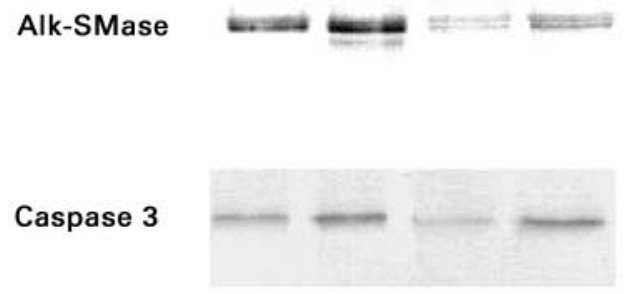

(b)
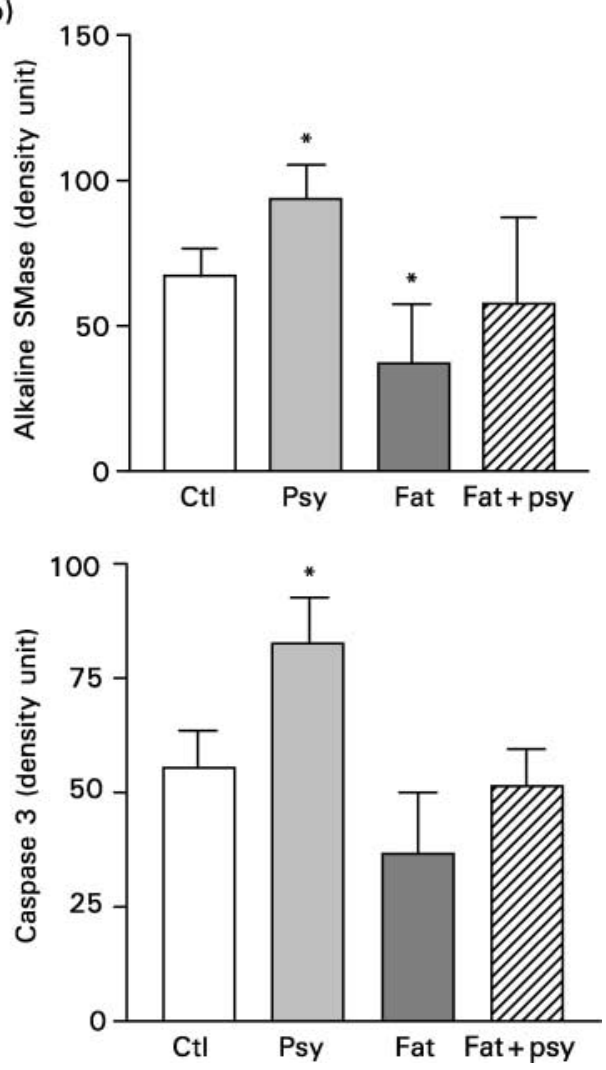

Fig. 3. Expression of alkaline (alk) sphingomyelinase (SMase) and caspase 3 in mice (twelve per group) fed control (Ctl), psyllium-containing (Psy), high-fat (Fat) or high-fat plus psyllium (Fat + psy) diets for 4 weeks. The colonic mucosa was scraped and homogenised. Four animals in each group were randomly selected for Western blotting analysis. In each lane, $50 \mu \mathrm{g}$ sample proteins were loaded. For details of diets and procedures, see Tables 1 and 2 and pp. 716-717. (a), A representative result of Western blotting. Lane A, Ctl; lane B, Psy; lane C, Fat; lane D, Fat + psy. (b), Quantification of the band densities by Scion Image software (Scion Co.; www.scioncorp.com). Values are means with standard deviations shown by vertical bars. Mean values were significantly different from those of the control group: ${ }^{*} P<0.05$.

high-psyllium diet significantly reduced ceramidase activity by $50 \%(P<0.001)$ and the high-fat diet reduced ceramidase activity by about $30 \%$ (NS). Combination of high-fat and psyllium gave a $62 \%$ reduction in ceramidase activity $(P<0 \cdot 001)$.

Correlation of caspase 3 activity with sphingomyelinase and ceramidase

To investigate whether there was a link between caspase 3 with any of the SMase and ceramidase, the correlation of 


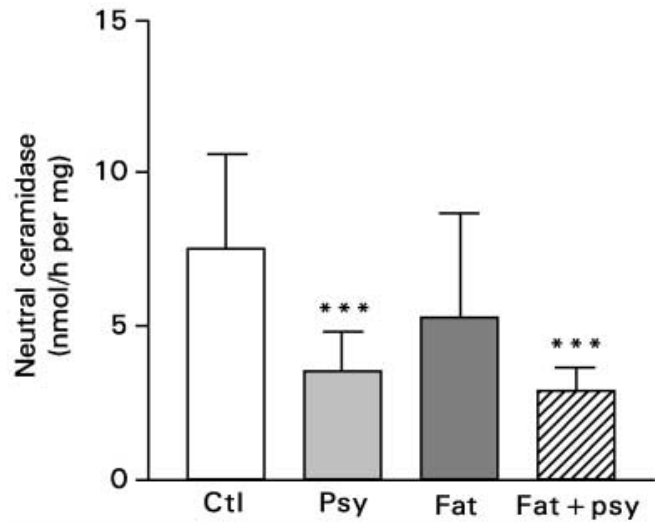

Fig. 4. Activities of neutral ceramidase in mice (twelve per group) fed control (Ctl), psyllium-containing (Psy), high-fat (Fat) or highfat + psyllium (Fat + psy) diets for 4 weeks. The colonic mucosa was homogenised and the activity of neutral ceramidase was determined. For details of diets and procedures, see Tables 1 and 2 and pp. 716-717. Values are means with standard deviations shown by vertical bars. Mean values were significantly different from that of the control group: ${ }^{\star \star \star} P<0.001$.

the activities of SMase and caspase 3 in all the animals was analysed and the results are shown in Fig. 5. The activity of caspase 3 was found to correlate positively with alkaline SMase $(P<0.0001)$ and negatively with acid SMase $(P<0 \cdot 0001)$. Similar correlation of caspase 8 or 9 with alkaline and acid SMase was also identified (results not shown). However, there was no correlation between the activity of neutral SMase and any caspase. In addition, there was no correlation between ceramidase activity and caspase activities (results not shown).

Activities of acid and alkaline phosphatase in the gut and acid and neutral sphingomyelinase in the liver

To assess the specificity of the changes of SMase induced by the diets in the colon, the activities of acid and alkaline phosphatase in the colonic mucosa and those of acid and neutral SMase in the liver after feeding these diets were determined. As shown in Table 4, the activities of both acid and alkaline phosphatase were decreased by the high-fat diet $(P<0.0001$ and $P<0.005$ respectively). The decreases were not restored by addition of psyllium to the high-fat diet. Table 5 shows that these diets had no effect on either acid or neutral SMase activities in the liver.

\section{Discussion}

In the present work we demonstrated that a psyllium-containing and a high-fat diet affected the activities of the enzymes that are responsible for SM metabolism and apoptosis in the colon. The psyllium-containing diet increased the activities of alkaline SMase and caspase, and decreased those of acid SMase and neutral ceramidase. The high-fat diet gave, in general, effects opposite to those of psyllium, decreasing the activities of alkaline SMase and caspase and increasing that of acid SMase. The change of alkaline SMase correlated positively and that of acid SMase negatively with the activity of caspase 3 , the key enzyme in execution phase of apoptosis.
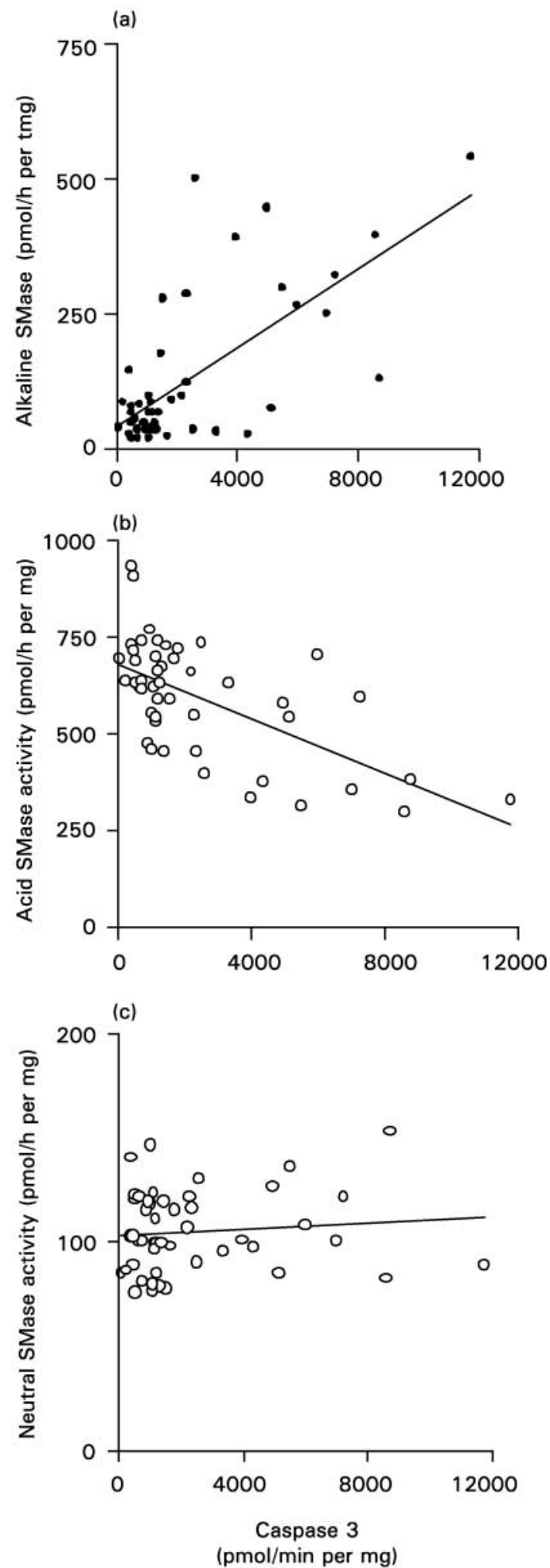

Fig. 5. Correlation of caspase 3 with acid, neutral and alkaline sphingomyelinase (SMase) in mice (twelve per group) fed control (Ctl), psyllium-containing (Psy), high-fat (Fat) or high-fat + psyllium (Fat + psy) diets for 4 weeks. The activities of acid, neutral and alkaline SMase and caspase 3 in the intestinal mucosa were determined. For details of diets and procedures, see Tables 1 and 2 and pp. 716-717. The correlations of caspase 3 activity with SMase were: (a), $r^{2} 0.4735, P<0.0001$; (b), $r^{2} 0.3914, P<0.0001$; (c), $r^{2}$ $0.01072, P=0.4838$. 
Table 4. The activities (unit/mg per $\mathrm{h}$ ) of acid and alkaline phosphatases in colonic mucosa of mice fed various diets for 4 weeks $†$ (Mean values and standard deviations for twelve mice per group)

\begin{tabular}{|c|c|c|c|c|}
\hline \multirow[b]{2}{*}{ Diet } & \multicolumn{2}{|c|}{ Acid phosphatase } & \multicolumn{2}{|c|}{$\begin{array}{c}\text { Alkaline } \\
\text { phosphatase }\end{array}$} \\
\hline & Mean & SD & Mean & SD \\
\hline Control & 1.321 & 0.232 & 0.816 & 0.678 \\
\hline Psyllium & 1.247 & 0.215 & 0.353 & 0.498 \\
\hline High-fat & $0.865^{\star \star}$ & 0.090 & $0.102^{*}$ & 0.163 \\
\hline High-fat + psyllium & $0.679^{\star \star}$ & 0.080 & $0.022^{*}$ & 0.007 \\
\hline
\end{tabular}

Mean values were significantly different from those of the control group: ${ }^{\star} P<0.005,{ }^{* *} P<0.0001$

†The colonic mucosa was homogenised and the activities of acid and alkaline phosphatase were determined. For details of diets and procedures, see Tables 1 and 2 and p. 716.

Table 5. Acid and neutral sphingomyelinase activities (pmol/h per $\mathrm{mg}$ ) in the liver in mice fed various diets for 4 weeks*

(Mean values and standard deviations for twelve mice per group)

\begin{tabular}{lccccr}
\hline \multirow{2}{*}{ Diet } & \multicolumn{2}{c}{ A-Smase } & & \multicolumn{2}{c}{ N-SMase } \\
\cline { 2 - 3 } & Mean & SD & & Mean & SD \\
\hline Control & 312.5 & 95.2 & & 78.7 & 11.1 \\
Psyllium & 366.2 & 90.7 & & 81.0 & 9.0 \\
High-fat & 356.7 & 81.0 & & 80.1 & 8.0 \\
High-fat + psyllium & 377.9 & 87.5 & & 85.5 & 8.3
\end{tabular}

A, acid; SMase, sphingomyelinase; $\mathrm{N}$, neutral.

* The liver was homogenised and SMase activity determined. For details of diets and procedures, see Tables 1 and 2 and pp. 716-717.

SM metabolism has emerged as a novel signal transduction pathway affecting cell proliferation and apoptosis. The most important lipid messenger derived from SM metabolism is ceramide, which is generated by hydrolysis of SM by SMase or by biosynthesis. Ceramide has been found to inhibit cell proliferation and induce cell differentiation and apoptosis. In general, apoptosis can be accomplished by two major pathways. One pathway is started by the binding of the death receptor, followed by aggregation and activation of caspase 8 . The other pathway involves the changes of membrane potential of mitochondria, leading to release of cytochrome $c$ and activation of caspase 9. Both caspase 8 and 9 are initiator caspases that will activate caspase 3 downstream, leading to apoptosis. Caspase 3 is the executor of apoptosis, which plays a key role in induction of apoptosis (Reed et al. 1996). Under physiological conditions, colonic epithelial cells are rapidly renewing and apoptosis is a critical event in controlling overall colonic tissue homeostasis. The nutritional influence on the apoptotic process has been only addressed recently (Lipkin et al. 1999). Our present study showed that the psyllium-containing diet increased caspase activity, indicating the spontaneous apoptotic rate in the colon may be increased by a psyllium-containing diet. The increased caspase 3 activity may be mainly caused by an increased synthesis of the enzyme, as Western blot showed an increased content of caspase 3 precursor in parallel with caspase 3 activity. Caspase 3 is synthesised as a precursor and its activation involves cleavage of a
$12 \mathrm{kDa}$ subunit. In the present study, Western blotting failed to identify the cleaved subunit of caspase 3 , probably due to the degradation of the subunit during the preparation of the colonic homogenates from the organ. In contrast to psyllium, the high-fat diet decreased both activity and expression of caspase 3 and also significantly reduced the activities of caspase 8 and 9, two initiator caspases. Thus, a high-fat diet is an inhibitor of apoptosis in the colonic mucosa and it can attenuate the pro-apoptotic effect of psyllium.

Although the mechanism by which psyllium and fat affect caspase activity is not clear, the changes in alkaline SMase activity may be a factor responsible for the altered caspase activity. In the intestinal tract, alkaline SMase is the major enzyme responsible for hydrolysis of both endogenous and exogenous SM (Nyberg et al. 1997). An increase in alkaline SMase activity by psyllium could elevate the generation of ceramide, which has been shown to induce apoptosis in colonic cells (Veldman et al. 1998) and enhance the activities of caspase 3 and 8 in other types of cells (Yoshimura et al. 1998; Farina et al. 2000; Rodriguez-Lafrasse et al. 2001). This hypothesis is supported by the positive correlation of alkaline SMase and caspase 3 . The finding is in agreement with one of our previous studies, which showed a positive correlation of alkaline SMase with caspase 3 in rat colon after administration of ursodeoxycholic acid (Cheng et al. 1999), a bile salt that has anti-carcinogenic effect in the colon (Earnest et al. 1994).

Acid SMase was increased by the high-fat diet and decreased by psyllium in the diet. Acid SMase is a type of lysosomal enzyme and its major function is thought to be hydrolysis of the endocytosed SM. The signalling effect of acid SMase is still a matter of debate (Levade \& Jaffrézou, 1999), although in some cell lines such as MCF-7 cells (Chatterjee \& Wu, 2001) and murine macrophages (Manthey \& Schuchman, 1998; Gomez-Munoz et al. 2003) acid SMase was implied to be involved in apoptosis. In human colon cancer tissues, the apoptotic effect of acid SMase has not been reported. In the present study, we found a negative correlation of acid SMase with caspase 3, indicating that acid SMase, by an unknown mechanism, may inhibit colonic apoptosis. It is known that there are different SM pools in the cells that are targeted by different SMase. The final outcome induced by different SMase depends on which SMase is activated, where the ceramide is generated, and what downstream targets are affected by ceramide (Andrieu-Abadie \& Levade, 2002; Pettus et al. 2002). In addition, the changes in opposite directions of alkaline and acid SMase caused by fat and psyllium implies a cross-regulation of these two SMase. How the regulations are orchestrated is of interest in further investigations.

The mechanisms by which psyllium and a high-fat diet induce the changes in SMase are not clear. Ingestion of psyllium has been found to have multiple effects in the intestinal tract, including generating SCFA (Clausen et al. 1991; Edwards \& Eastwood, 1995), providing colonic flora with energy and changing the bile acid composition (Trautwein et al. 1998). Some of these secondary effects may be involved in increasing the activities of alkaline SMase. 
Although the specific factors responsible are unknown, it is clear that the alterations caused by psyllium and fat were not a result of non-specific effects of these agents on lysosomal or brush border enzymes, because the activities of intestinal acid and alkaline phosphatase were not changed in a parallel way. Both acid phosphatase and acid SMase are lysosomal enzymes and both alkaline phosphatase and alkaline SMase are brush border enzymes. Furthermore, the changes in SMase by the diets were also tissue specific and not related to a change in fat absorption, as acid SMase in the liver was not affected by these diets. The alkaline SMase in the mouse liver was not determined, as the enzyme is not expressed in the liver and bile except in human subjects (Duan et al. 1996; Cheng et al. 2002). Put together, the opposite effects of psyllium-containing and high-fat diets on different types of SMase and caspase indicate a potential biochemical mechanism underlying the differential effects of fat and fibre on tumourigenesis and inflammation in the colon.

\section{Acknowledgements}

The authors thank Dr Horst-Dietmar Tauschel for providing the psyllium, Dr Lena Nyberg for providing radiolabelled sphingomyelin, Dr Marie Mutanen for designing the diets and DrAke Nilsson for helpful discussions. The study was supported by grants from Swedish Cancer Foundation, Swedish Research Council, Albert Påhlsson Foundation, Swedish Medicine Association, Lund University Hospital Research Foundation and Dr Falk Pharma GmbH Foundation.

\section{References}

Alabaster O, Tang ZC, Frost A \& Shivapurkar N (1993) Potential synergism between wheat bran and psyllium: enhanced inhibition of colon cancer. Cancer Lett 75, 53-58.

Andrieu-Abadie N \& Levade T (2002) Sphingomyelin hydrolysis during apoptosis. Biochim Biophys Acta 1585, 126-134.

Bielawska A \& Hannun YA (2000) Preparation of radiolabeled ceramides and phosphosphingolipids. Methods Enzymol 311, 499-518.

Blank M, Cress EA, Smith ZL \& Snyder F (1992) Meats and fish consumed in the American diet contain substantial amounts of ether-linked phospholipids. J Nutr 122, 1656-1661.

Chatterjee M \& Wu S (2001) Involvement of Fas receptor and not tumor necrosis factor-alpha receptor in ultraviolet-induced activation of acid sphingomyelinase. Mol Carcinog 30, 47-55.

Cheng Y, Nilsson A, Tömquist E \& Duan RD (2002) Purification, characterization and expression of rat intestinal alkaline sphingomyelinase. J Lipid Res 43, 316-324.

Cheng Y, Tauschel HT, Nilsson ^ \& Duan RD (1999) Administration of ursodeoxycholic acid increases the activities of alkaline sphingomyelinase and caspase-3 in rat colon. Scand $J$ Gastroenterol 34, 915-920.

Clausen MR, Bonnen H \& Mortensen PB (1991) Colonic fermentation of dietary fibre to short chain fatty acids in patients with adenomatous polyps and colonic cancer. Gut 32, 923-928.

Cohen LA, Zhao Z, Zang EA, Wynn TT, Simi B \& Rivenson A (1996) Wheat bran and psyllium diets: effects on N-methylnitrosourea-induced mammary tumorigenesis in F344 rats. $J$ Natl Cancer Inst 88, 899-907.
Dillehay DL, Webb SK, Schmelz E-M \& Merrill AH (1994) Dietary sphingomyelin inhibits 1,2-dimethylhydrazine-induced colon cancer in CF1 mice. J Nutr 124, 615-620.

Duan RD, Cheng Y, Hansen G, Hertervig E, Liu JJ, Syk I, Sjostrom H \& Nilsson $\AA$ (2003) Purification, localization, and expression of human intestinal alkaline sphingomyelinase. $J$ Lipid Res 44, 1241-1250.

Duan RD, Cheng Y, Yang L, Ohlsson L \& Nilsson Å (2001) Evidence for specific ceramidase present in the intestinal contents of rats and humans. Lipids 36, 807-812.

Duan RD, Hertervig E, Nyberg L, Tauge T, Sternby B, Lillienau J, Farooqi A \& Nilsson $\AA$ (1996) Distribution of alkaline sphingomyelinase activity in human beings and animals. Dig Dis Sci 41, 1801-1806.

Duan RD \& Nilsson Å (1999) Enzymes hydrolysing sphingolipids in gastrointestinal tract. Methods Enzymol 311, 276-286.

Duan RD, Nyberg L \& Nilsson $\AA$ (1995) Alkaline sphingomyelinase activity in rat gastrointestinal tract: distribution and characterization. Biochim Biophys Acta 1259, 49-55.

Earnest DL, Holubec H, Wali RK, Jolley CS, Bissonette M, Bhattacharyya AK, Roy H, Khare S \& Brasitus TA (1994) Chemoprevention of azoxymethane-induced colonic carcinogenesis by supplemental dietary ursodeoxycholic acid. Cancer Res 54, 5071-5074.

Edwards CA \& Eastwood MA (1995) Caecal and faecal shortchain fatty acids and stool output in rats fed on diets containing non-starch polysaccharides. Br J Nutr 73, 773-781.

Farina F, Cappello F, Todaro M, Bucchieri F, Peri G, Zummo G \& Stassi G (2000) Involvement of caspase-3 and GD3 ganglioside in ceramide-induced apoptosis in Farber disease. J Histochem Cytochem 48, 57-62.

Fernandez-Banares F, Hinojosa J, Sanchez-Lombrana JL, Navarro E, Martinez-Salmeron JF, Garcia-Puges A, Gonzalez-Huiz F, Riera J, Gonzalez-Lara V, Dominguez-Abascal F, et al. (1999) Randomized clinical trial of Plantago ovata seeds (dietary fiber) as compared with mesalamine in maintaining remission in ulcerative colitis. Spanish Group for the Study of Crohn's Disease and Ulcerative Colitis (GETECCU). Am $J$ Gastroenterol 94, 427-433.

Geerling BJ, Dagnelie PC, Badart-Smook A, Russel MG, Stockbrugger RW \& Brummer RJ (2000) Diet as a risk factor for the development of ulcerative colitis. Am J Gastroenterol 95, $1008-1013$

Gomez-Munoz A, Kong J, Salh B \& Steinbrecher UP (2003) Sphingosine-1-phosphate inhibits acid sphingomyelinase and blocks apoptosis in macrophages. FEBS Lett 539, 56-60.

Hannun YA \& Bell RM (1989) Functions of sphingolipids and sphingolipid breakdown products in cellular regulation. Science 243, 500-507.

Hertervig E, Nilsson Å, Björk J, Hultkrantz R \& Duan RD (1999) Familial adenomatous polyposis is associated with a marked decrease in alkaline sphingomyelinase activity; a key factor to the unrestrained cell proliferation. Br J Cancer 81, 232-236.

Hertervig E, Nilsson Å, Nyberg L \& Duan RD (1996) Alkaline sphingomyelinase activity is decreased in human colorectal carcinoma. Cancer 79, 448-453.

Kanauchi O, Suga T, Tochihara M, Hibi T, Naganuma M, Homma T, Asajura H, Nakano H, Takahama K, Fujiyama Y, et al. (2002) Treatment of ulcerative colitis by feeding with germinated barley foodstuff: first report of a multicenter open control trial. J Gastroenterol 37, Suppl. 14, 67-72.

Kim Y-I (2000) AGA technical review: impact of dietary fiber on colon cancer occurrence. Gastroenterology 118, $1235-1257$.

Kolesnick RN (1991) Sphingomyelin and derivatives as cellular signals. Prog Lipid Res 30, 1-38. 
Levade T \& Jaffrézou J-P (1999) Signalling sphingomyelinase: which, where, how and why? Biochim Biophys Acta 1438, 1-17.

Lipkin M, Reddy B, Newmark H \& Lamprecht S (1999) Dietary factors in human colorectal cancer. Annu Rev Nutr 19 $545-586$.

Liu JJ, Nilsson A, Oredsson S, Badmaev V, Zhao WZ \& Duan RD (2002) Boswellic acids trigger apoptosis via a pathway dependent on caspase- 8 activation but independent on Fas/ Fas ligand interaction in colon cancer HT-29 cells. Carcinogenesis 23, 2087-2093.

Lundgren P, Nilsson A \& Duan RD (2001) Distribution and properties of neutral ceramidase activity in rat intestinal tract. Dig Dis Sci 46, 765-772.

Manthey CL \& Schuchman EH (1998) Acid sphingomyelinasederived ceramide is not required for inflammatory cytokine signalling in murine macrophages. Cytokine 10, 654-661.

Merrill AH Jr, Schmelz EM, Dillehay DL, Spiegel S, Shayman JA, Schroeder JJ, Riley RT, Voss KA \& Wang E (1997) Sphingolipids - the enigmatic lipid class: biochemistry, physiology, and pathophysiology. Toxicol Appl Pharmacol 142, $208-225$.

Nilsson $\AA$ (1969) The presence of sphingomyelin- and ceramidecleaving enzymes in the small intestinal tract. Biochim Biophys Acta 176, 339-347.

Nyberg L, Nilsson Å, Lundgren P \& Duan RD (1997) Localization and capacity of sphingomyelin digestion in the rat intestinal tract. J Nutr Biochem 8, 112-118.

Pajari A-M \& Mutanen M (1999) Phospholipid fatty acid composition and protein kinase $\mathrm{C}$ activity in the large intestine of rats fed on butter and coconut-oil diets. Br J Nutr 82, 411-418.

Pettus BJ, Chalfant CE \& Hannun YA (2002) Ceramide in apoptosis: an overview and current perspectives. Biochim Biophys Acta 1585, 114-125.

Reddy BS, Hirose Y \& Rao CV (2003) Types of dietary fat and colon cancer risk. In Exogenous Factors in Colonic Carcinogenesis, pp. 120-127 [W Scheppach and M Scheurlen, editors]. Dordrecht/Boston/London: Kluwer Acad. Pub.

Reed JC, Miyashita T, Takayama S, Wang HG, Sato T, Krajewski S, Aime-Sempe C, Bodrug S, Kitada S \& Hanada M (1996) BCL-2 family proteins: regulators of cell death involved in the pathogenesis of cancer and resistance to therapy. J Cell Biochem 60, 23-32.

Reeves PG, Nielsen FH \& Fahey GC Jr (1993) AIN-93 purified diets for laboratory rodents: final report of the American Institute of Nutrition ad hoc writing committee on the reformulation of the AIN-76A rodent diet. J Nutr 123, 1939-1951.

Reif S, Klein I, Lubin F, Farbstein M, Hallak A \& Gilat T (1997) Pre-illness dietary factors in inflammatory bowel disease. Gut 40, 754-760.

Robert-Andersen J, Mehta T \& Wilson RB (1987) Reduction of DMH-induced colon tumors in rats fed psyllium husk or cellulose. Nutr Cancer 10, 129-136.

Rodriguez-Lafrasse C, Alphonse G, Broquet P, Aloy MT, Louisot P \& Rousson R (2001) Temporal relationships between ceramide production, caspase activation and mitochondrial dysfunction in cell lines with varying sensitivity to anti-Fasinduced apoptosis. Biochem J 357, 407-416.

Sjöqvist U, Hertervig E, Nilsson $\AA$, Duan RD, Ost A, Tribukait B \& Lofberg R (2002) Chronic colitis is associated with a reduction of mucosal alkaline sphingomyelinase activity. Inflamm Bowel Dis 8, 258-263.

Trautwein EA, Rieckhoff D, Kunath-Rau A \& Erbersdobler HF (1998) Psyllium, not pectin or guar gum, alters lipoprotein and biliary bile acid composition and fecal sterol excretion in the hamster. Lipids 33, 573-582.

Veldman RJ, Klappe K, Hoekstra D \& Kok JW (1998) Metabolism and apoptotic properties of elevated ceramide in HT29rev cells. Biochem J 331, 563-569.

Yang L, Mutanen M, Cheng Y \& Duan RD (2002) Effects of red meat and fiber in high fat diet on activities of sphingomyelinase, ceramidase and caspase- 3 in rat colonic mucosa. $J$ Nutr Biochem 13, 499-504.

Yoshimura S, Banno Y, Nakashima S, Takenaka K, Sakai H, Nishimura Y, Sakai N, Shimizu S, Eguchi Y, Tsujimoto Y, et al. (1998) Ceramide formation leads to caspase-3 activation during hyposic PC12 cell death. Inhibitory effects of Bcl-2 on ceramide formation and caspase-3 activation. J Biol Chem 273, 6921-6927.

Zeisel SH, Char D \& Sheard NF (1986) Choline phosphatidylcholine and sphingomyelin in human and bovine milk and infant formulas. $J$ Nutr 116, 50-58. 